\title{
Zirconia in the Service of Anterior Aesthetic Restorations
}

\author{
Sihem Hajjaji ${ }^{1}$, Rihab Dakhli ${ }^{2}$, Hayet Hajjemi ${ }^{1}$, Abdellatif Boughzela ${ }^{1}$ \\ ${ }^{1}$ Department of Dentistry, Farhat Hached University Hospital, Sousse/ Tunisia \\ ${ }^{2}$ Fixed Prosthesis Department, Dental School, Monastir/ Tunisia \\ Corresponding Author: Sihem Hajjaji
}

\begin{abstract}
Introduction: Zirconia appears in odontology fifteen years ago under the form of a screed covered with feldspathic ceramic, as an alternative to the ceramic-metal crown. The success of zirconia stems from its biocompatibility and aesthetic potential in combination with optimized mechanical properties. For years, zirconia was the benchmark for the restoration of the posterior sector. Today translucent zirconia is offered to satisfy aesthetic demands even at the previous level

Observation: The 54-year-old HA patient consulted for the replacement of her old ceramic-metal bridge in the anterior sector. Its motif was both aesthetic and functional. The therapeutic choice was directed towards the creation of metal ceramic bridge with a zirconia coping. The clinical steps necessary for this prosthetic design will be detailed step by step.

Discussion: Several ceramics are now available to us for aesthetic anterior restorations. However, the choice of the appropriate ceramic is not only guided by aesthetic needs. Other parameters must be taken into consideration such as the situation of the finish line, the height of the stumps ... Zirconia may not seem like the ideal ceramic for anterior restorations. However, when the case requires, we can opt for an "improved" zirconia giving wide aesthetic satisfaction
\end{abstract}

Key words: zirconia, aesthetics, translucency, opacity, density.

\section{INTRODUCTION}

Zirconia is one of the materials that has undergone particularly rapid and significant development, particularly with the democratization of computer-aided design and manufacturing (CAD / CAM). For years, zirconia was considered to be the material of choice for the development of infrastructures at the later level and this thanks to its excellent mechanical properties.

In recent years, the use of zirconia has shifted to the prior sector. In this indication, the reflective nature of zirconia posed a major aesthetic problem and it therefore became essential to improve its translucency.

Translucent zirconia with strengths of around 800MPa were then developed for posterior monolithic restorations. Today very high translucency versions are available. The latter are experiencing exponential development and allow stunning anterior aesthetics, even in the case of restorations without layering.

\section{OBSERVATION}

Patient HA, aged 54, consulted our fixed prosthesis unit for mobility of her ceramic-metal bridge made almost ten years ago (fig. 1). During questioning, the patient expressed her dissatisfaction with the aesthetic appearance of her bridge.

Oral examination revealed a ceramic-metal bridge replacing the two mandibular central incisors and resting on the two mandibular lateral incisors. The general morphology of the bridge did not 
meet standard aesthetic standards for an anterior fixed prosthesis. A shift of the interincisal line was noted with no contact point on the distal side.

The bridge presented degree 3 of mobility with pain felt at the slightest touch. Our course of action was first of all directed towards atraumatic removal of the bridge and evaluation of the residual support teeth.

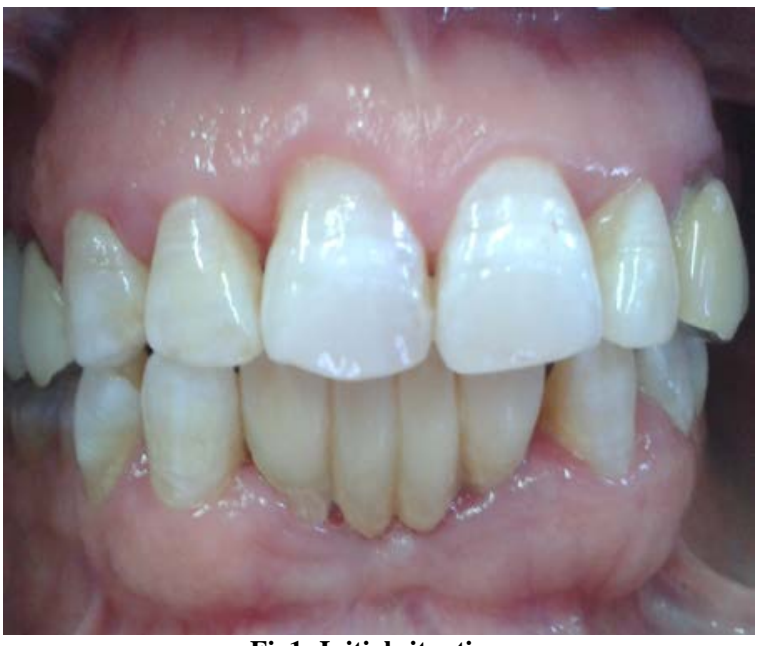

Fig1: Initial situation

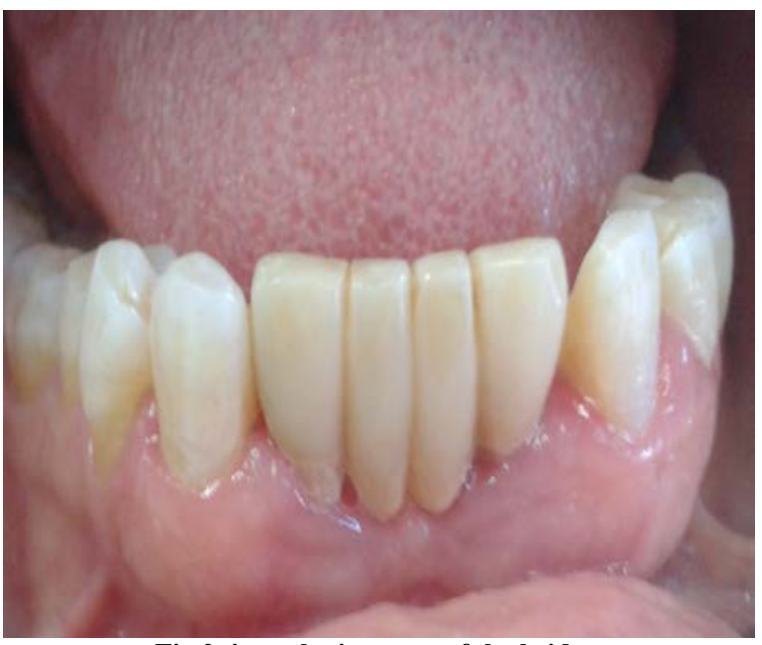

Fig.2: ineasthetic aspect of the bridge

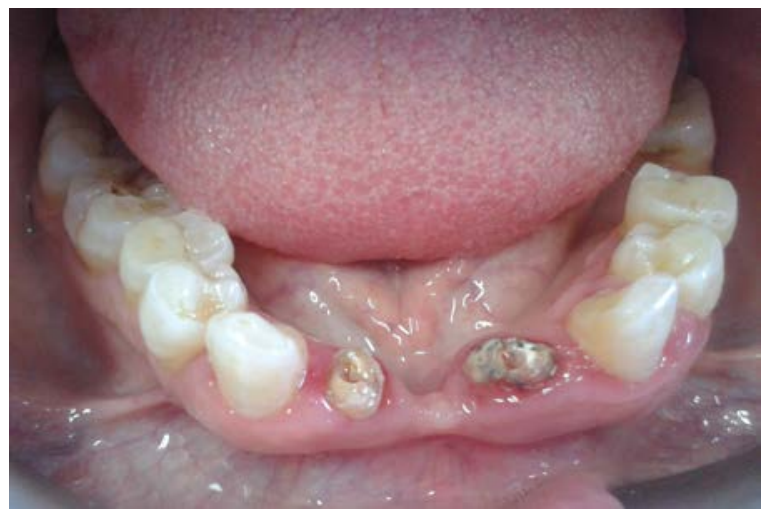

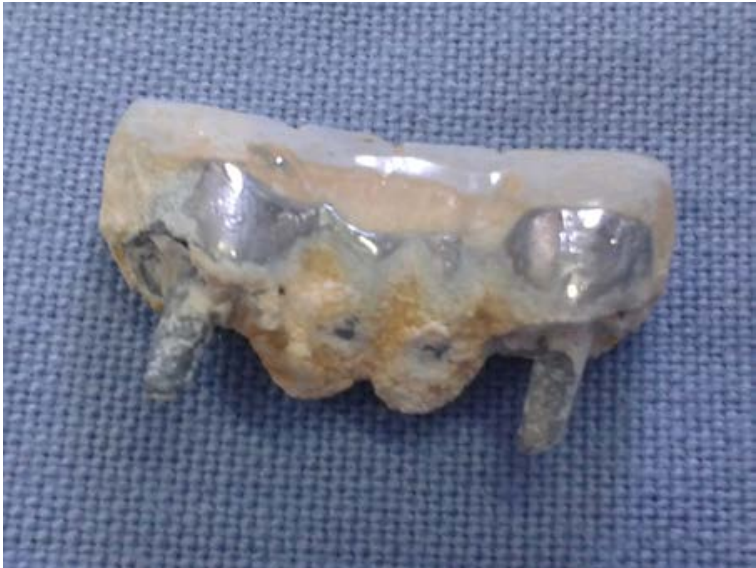

Fig3: note the accumulation of tartar and the too short length of the posts

\section{Haut du formulaire}

The condition of the dismantled bridge explained the increased mobility justified by a lack of retention due to the use of too short posts that did not sufficiently exploit the length of the roots. A deposit of tartar on the entire gingival surface of the pontic explained the inflammatory state of the edentulous ridge (fig. 3). The state of the residual supporting teeth justified their extraction: sub-total disrepair (fig. 4a, b), support periodontal reduced with a longitudinal fracture at the level of 32 (fig. 5). After comparing all the data, the prosthetic choice turned towards the creation of a ceramic-ceramic bridge with zirconia copings replacing the four mandibular incisors and taking 33 and 43 as supporting teeth. The clinical protocol began with the preparation of the supporting teeth (fig6.a, b). This preparation met the main principles of all-ceramic prostheses. Subsequently, a temporary prosthesis in baked resin was used to protect the prepared teeth.

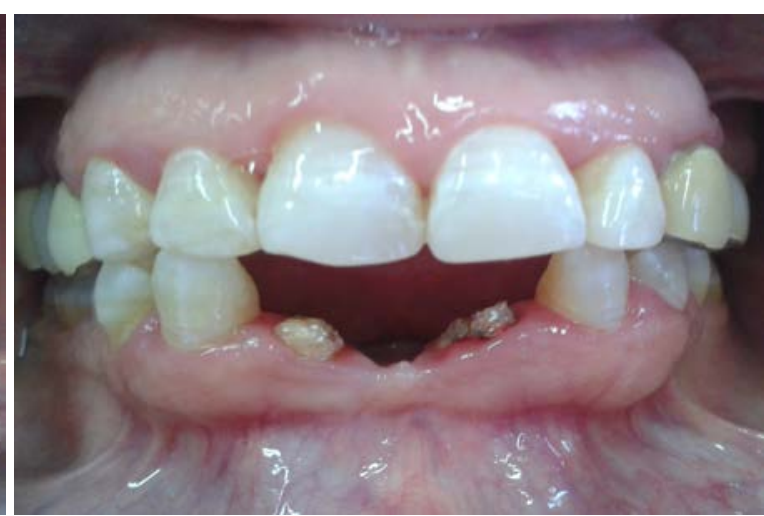

Fig. 4.a, b: Endo-oral view of the supporting teeth after removal of the old bridge 


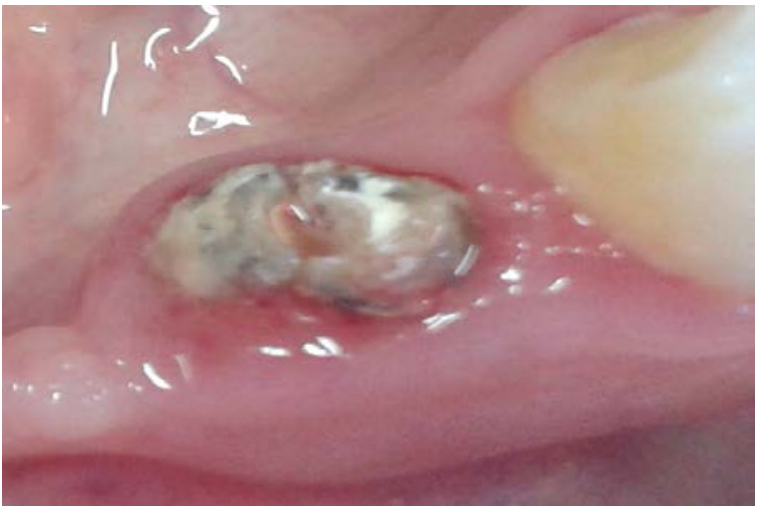

Fig. 5: Longitudinal fracture at the level of 32
At this timeout period, the provisional prosthesis was modified several times depending on the patient's complaints, both aesthetically and functionally. At the end of this phase, the patient clearly expressed her full satisfaction, which enabled us to consider this bridge as a prototype for her final prosthesis (Fig. 7a, b). The imprint of the preparations was taken during the same session, guaranteeing a faithful reproduction of the details (fig. 8).
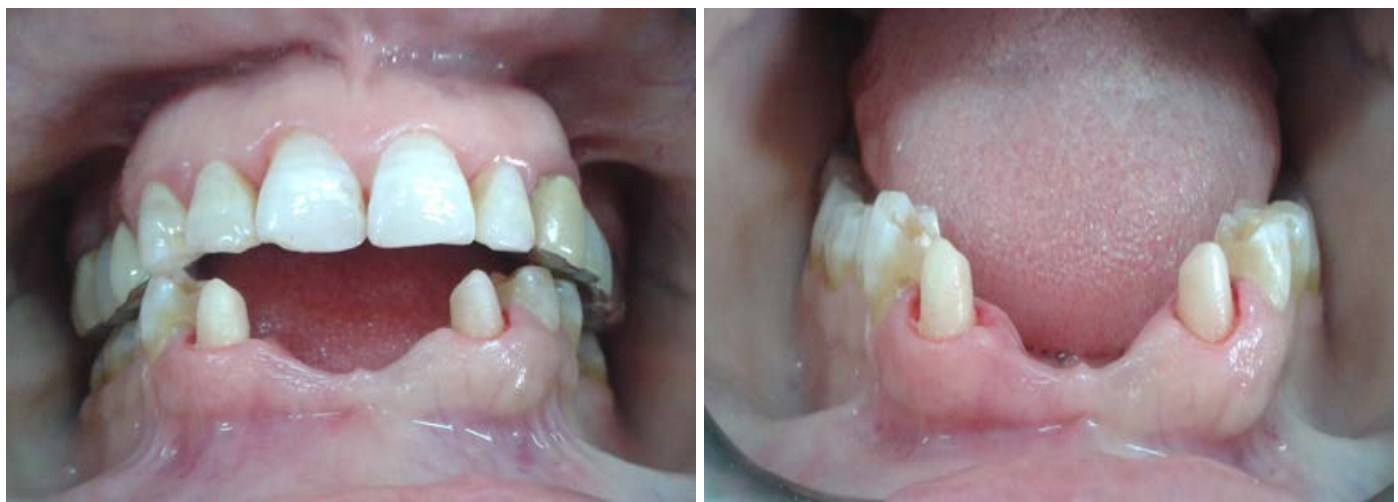

Fig. 6a, b: Preparations of the supporting teeth (33 and 43) respecting the standard principles of all-ceramic prostheses
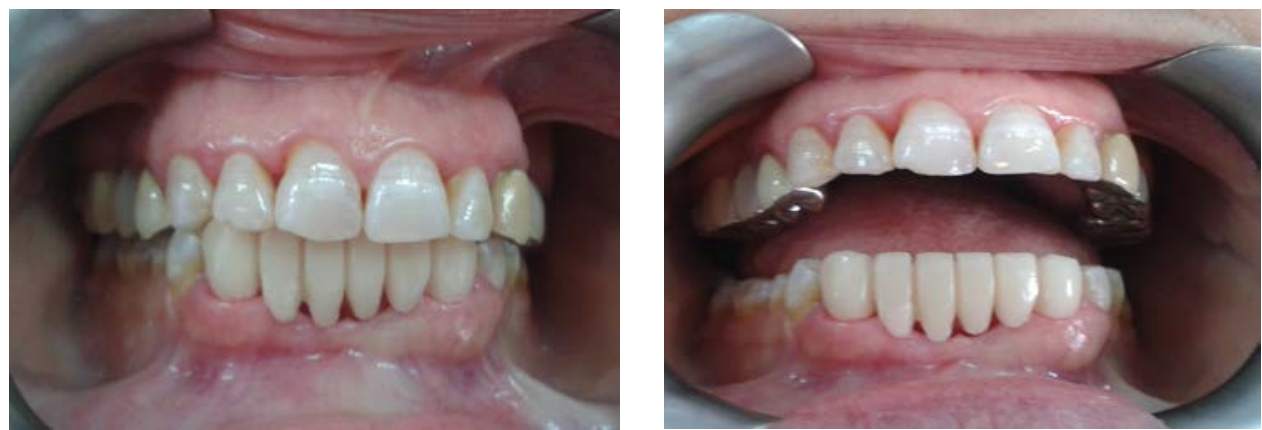

Fig. 7a,b

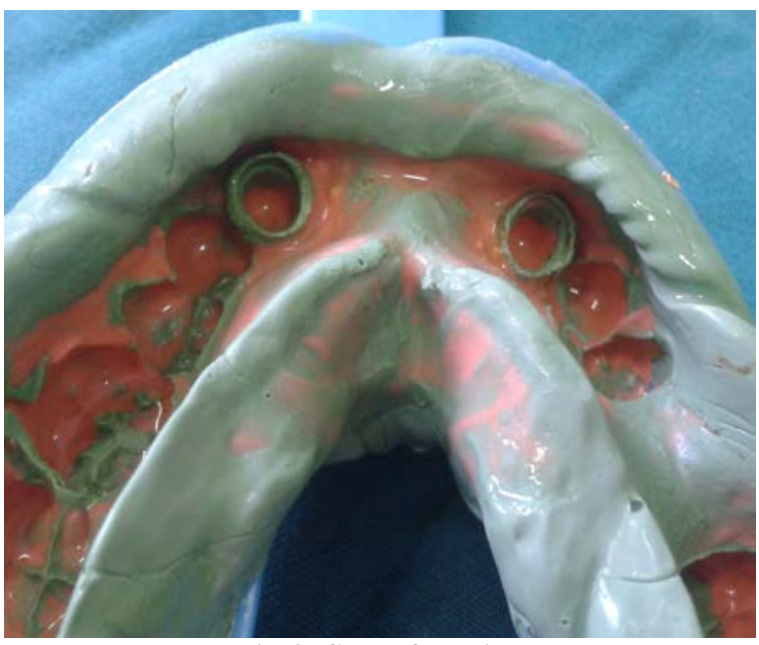

Fig. 8: Global footprint
The zirconia coping of the bridge was tested on its model, then in the mouth: the points that were verified are the adaptation of the cervical limits, the retention and stability of the coping, as well as the space left for the veneering ceramic. (fig. 9.a, b, c, d).

The choice was made on the shade of the two maxillary central incisors, since the patient planned to redo her two right and left maxillary lateral prostheses, and in order to optimize the final aesthetic result, an external teeth whitening was planned. The finished bridge was sealed using CVIMAR. The final aesthetic result was 
very satisfactory for both the patient and the whole team (Fig. 10).

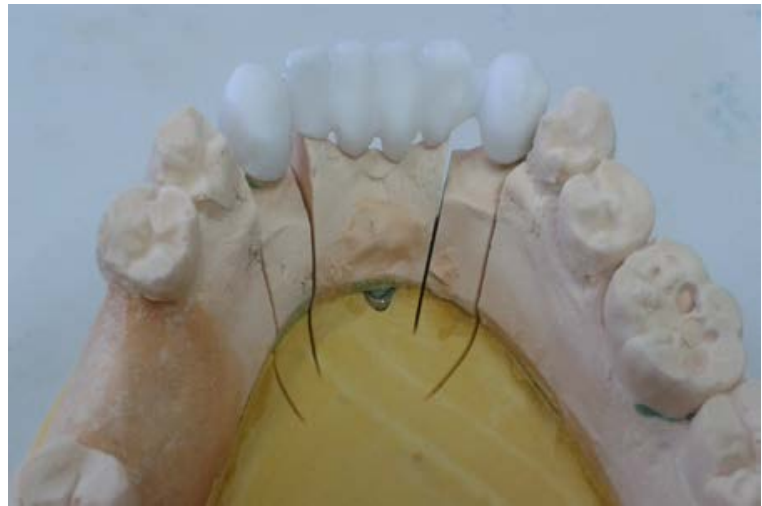

$\mathbf{a}$

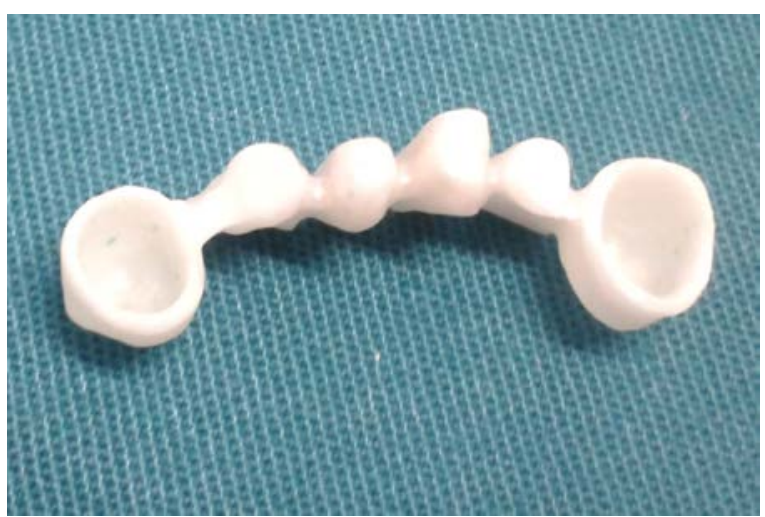

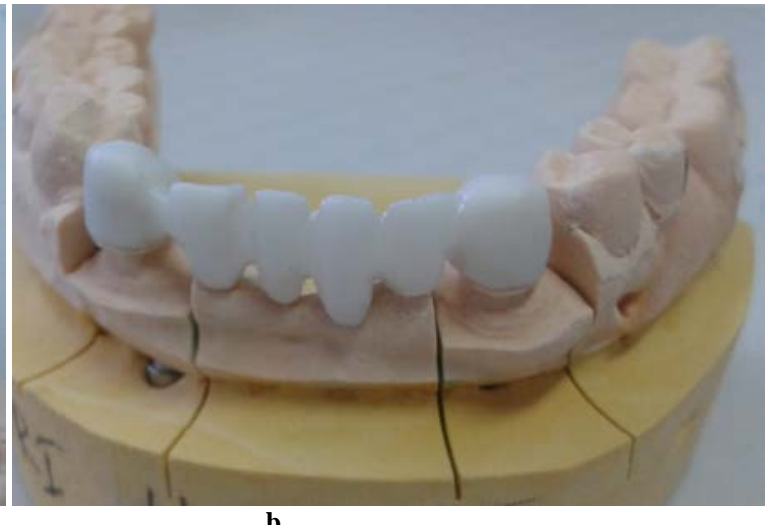

b

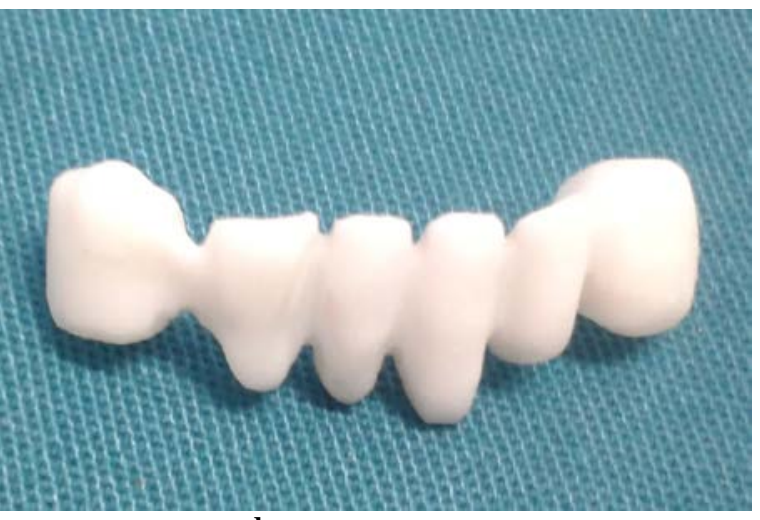

Fig. 9.a, b: Coping of the zirconia bridge on a working model c: Extrados of the zirconia coping d: Intrados of the zirconia screed

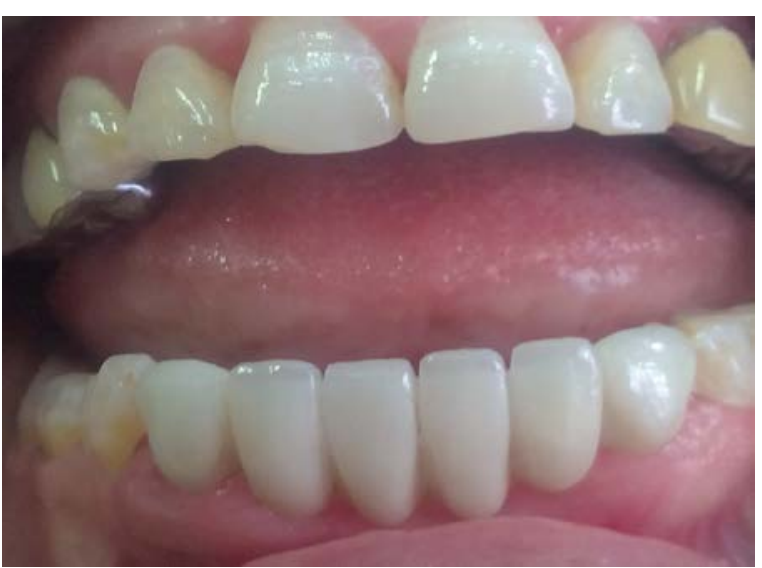

Fig.10: Final aesthetic result after adhesive cementation of the zirconia bridge

\section{DISCUSSION}

In the case below, the choice of ceramic material was a delicate task. Indeed, the multiplicity of materials available today leads us to make a precise choice in order to best respond to the clinical situation that presents itself to us. It was through a critical analysis of the interests and limitations of zirconia that we made our choice:
Aesthetic interest: This is the major interest of restoration. Zirconia meets the "aesthetic" specifications. However, it is important to note that this is not the ideal framework ceramic in the anterior sector due to its low translucency. Indeed, it is the most opaque ceramic. This opacity is essential.

It is the result of the ratio between reflected light intensity and transmitted light intensity. The more opaque the material, the less light is transmitted. Currently, laboratories propose to color zirconia copings (either by dipping or by applying a dye with a brush).

This allows increased mimicry with the different forms of coronary preparations intended to receive all-ceramic reconstructions with a zirconia framework. Other laboratories suggest covering the screed with an "opaque liner" in order to reduce this luminosity. Several coats can be 
applied in order to adapt the color with the adjacent teeth, and this, for an optimal aesthetic result.

Other labs, pancreatic zirconia, change its composition by lowering the proportion of Al2O3, making the zirconia semi-transparent. For other manufacturers, the thickness of the framework is the most important component of aesthetic aspect and the translucency of the prosthesis. Indeed, a $0.5 \mathrm{~mm}$ thick lava zirconia coping will have the same translucency as an empress II ceramic $0.8 \mathrm{~mm}$. Beyond this thickness, the opacity gradually increases.

As we have seen therefore, several techniques are proposed today to improve the translucency of zirconia. However, it should be noted that the aesthetic result of a prosthesis is always very subjective, whether in terms of color or shape. Indeed, the experience of the operators (practitioner and prosthetist) is essential in the final success and integration of the restoration.

The observation of the natural shade and shape of teeth and their transmission to the laboratory is essential. Modern communication techniques: digital photographs and transmission via the Internet, constitute an important contribution. But the artistic sense of the prosthetist, his skill and his experience remain decisive for the final result. In addition, the observation of many parameters such as: the smile line, the type of periodontium, during the clinical examination is a step as essential as the choice of material in the aesthetic success of the project. zirconia is a parameter of this success. It is of major interest in its use in the prior sector.

\section{CONCLUSION}

Zirconia is considered today as an essential material in our therapeutic arsenal. Well - known for its mechanical resistance, research focused, with the advent of CAD / CAM, on zirconia prostheses with markedly improved aesthetics. Zirconia became thus a credible option both in the posterior sector and in the anterior sector. However, it should not be considered that its evolution is complete and its use i without risks. Certain difficulties persist; they must be mastered in order to be able to make zirconia a material of choice.

\section{Acknowledgement: None}

\section{Conflict of Interest: None}

\section{Source of Funding: None}

\section{REFERENCES}

1. Bulot D, Sadan A, Burgess JO, Blatz MB. Bond strength of a self-adhesive universal resin cement to Lava Zirconia after two surfaces treatments (IADR abstract), Goteborg. 2003

2. Souza R, Barbosa F, Araújo G, Miyashita E, Bottino M, Melo R, et al. Ultrathin Monolithic Zirconia Veneers: Reality or Future? Report of a Clinical Case and Oneyear Follow-up. Operative Dentistry. 1 janv 2018;43(1):3-11.

3. Preis V, Weiser F, Handel G, Rosentritt M. Wear performance of monolithic dental ceramics with different surface treatments. Quintessence Int Berl Ger 1985. 2013 ;44(5) :393- 405

4. Edelhoff D, Sorensen J. Light transmission though all-ceramic framework and cement combi- nations. IADR.2002/17

5. Zhang Y, Lawn BR. Novel Zirconia Materials in Dentistry. J Dent Res. 2018;97(2):140- 147.

6. Carrabba M, Keeling AJ, Aziz A, Vichi A, Fabian Fonzar R, Wood D, et al. Translucent zirconia in the ceramic scenario for monolithic restorations: A flexural strength and translucency comparison test. J Dent. 2017;60:70-6.

7. Manauta J, Salat A. Layers, chapter 10, Quintessence book, 2012

8. Raigrodski A. In: Clinical and laboratory considerations for achieving function and aesthetics with the Lava System. Spectrum International.

9. Uludag B, Usumez A, Sahin V, Eser K, Ercoban E. The effect of ceramic thickness and number of firings on the color of ceramic systems: an in vitro study. J Prosthet Dent. 2007; 97(1): 25-31.

10. Bazos P, Magne P. - Bio-emulation: biomimetically emulating nature utilizing a 
histoanatomic approach; structural analysis. European Journal of Esthetic Dentistry 2011, 6(1)

11. Manicone PF, Rossi Immoetti P et Raffaelli L. An overview of zirconia ceramics: basic properties and clinical applications. J Dent 2007;35(11):819-826.

12. Raffaelli L, Rossi Immoetti P, Piccioni E et coll. Growth viability, adhesion potential and fibronectine expression in fibroblasts cultured on zirconia or feldspathic ceramics in vitro. J Biomed Mater Res A 2008;86(4):959-968.

13. Porstendorfer J, Reineking A, Willert H.-G. Radiation risk estimation based on activity measurements of zirconium oxide implants. J Biomed Mater Res 1996;32;663-667.

14. Covacci V, Bruzzese N, Maccauro G et coll. In vitro evaluation of the mutagenic and carogenic power of high purity zirconia ceramic. Biomaterials 1999;20(4):371-376.

15. Silva VV, Lameiras FS et Lobato ZI. Biological reactivity of zirconiahydroxyapatite composites. J Biomed Mater Res 2002;63(5):583-590.
16. Kohal JR, Weng D, Bachle M, Strub JR. Loaded custom-made zirconia and titanium implants show similar osseointegration: an animal experiment. J Periodontol 2004;75(9):1262-1268.

17. Kou W, Molin M, Sjogren G. Surface roughness of five different dental ceramic core materials after grinding and polishing. J Oral Rehabil 2006;33(2):117-124.

18. Jung RE, Saila I, Hammerle $\mathrm{CH}$ et coll. In vitro color changes of soft tissues caused by restorative materials. Int J Periodont Rest Dent 2007 ;27(3) :251-257.

19. Saldana L, Mendez-Vilas A, Jiang L et coll. In vitro biocompatibility of an ultrafine grained zirconium. Biomaterials 2007; 28(30): 4343-4354.

How to cite this article: Hajjaji S, Dakhli R, Hajjemi $\mathrm{H}$ et.al. Zirconia in the service of anterior aesthetic restorations. Int $J$ Health Sci Res. 2021; 11(11): 124-129. DOI: https://doi. org/10.52403/ijhsr.20211115 